\title{
The Black report on socioeconomic inequalities in health 10 years on
}

\author{
George Davey Smith, Mel Bartley, David Blane
}

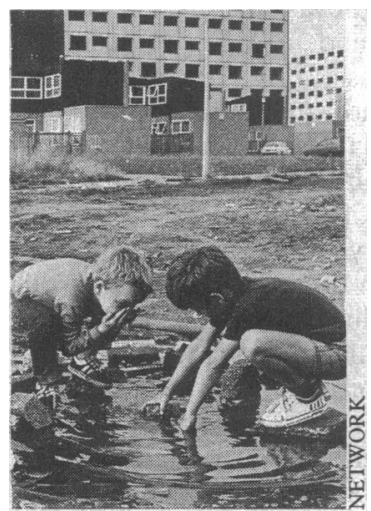

\begin{abstract}
Introduction
This month marks the 10th anniversary of the publication of the Black report.' In 1977 the Research Working Group on Inequalities in Health had been convened by David Ennals, then Secretary of State for Social Services, under the chairmanship of Sir Douglas Black, president of the Royal College of Physicians. Its findings were not welcomed by the government when they were published in August $1980,{ }^{23}$ but they generated great interest both in the United Kingdom and in other countries. Copies of the "Black report" were initially in short supply until Penguin published a paperback version, whose sales have ensured it a wide readership. ${ }^{+}$The central finding of the working group - that there were large differentials in mortality and morbidity that favoured the higher social classes and that were not being redressed by health or social services-became widely known. In the 10 years since its publication new information has become available in four areas in particular: the use of alternative measures of socioeconomic position to index mortality risk; the collection of morbidity data; the comparison of inequalities in Britain with those in other industrialised countries; and the understanding of the causes of the differentials. These four areas are reviewed in this paper.
\end{abstract}

\section{Mortality differentials RECENT TRENDS}

The Black report relied on analyses of mortality by social class from the 1970-2 decennial supplement on occupational mortality. ${ }^{5}$ The analysis of standardised mortality ratio reported in the subsequent decennial supplement indicated that mortality differentials had widened from 1971 to 1981 . Around 1971 for men aged 15-64 the standardised mortality ratio in social class $\mathrm{V}$ was 1.8 times that in social class $\mathrm{I}^{\mathrm{5}}$; around 1981 for men aged 20-64 the V:I ratio was $2 \cdot 4 .{ }^{67}$ The difference between the non-manual and the manual groups also increased, ${ }^{8}$ so the larger V:I ratio around 1981 was not due solely to the worsening relative mortality in social class $\mathrm{V}$. In addition, since the Black report appeared socioeconomic differentials in mortality in people over retirement age have been shown for the first time. ${ }^{9}$

An alternative mortality index to the stardardised mortality ratio is that of years of potential life lost, ${ }^{10} \mathrm{a}$ measure in which the contribution of deaths at an earlier age is increased. An analysis of the data in terms of years of potential life lost produced a greater V:I ratio around 1981 than did the standardised mortality ratio because such an analysis more fully reflected the predominance of deaths in the manual classes during the early years of working life. ${ }^{11}$ The data on cause of death showed the important contribution of accidents and violence to class inequalities in mortality.

In the introduction to the popular edition of the Black report the editors suggested that inequalities in

\section{Ten years after the Black report}

- Social class differences in mortality are widening

- Better measures of socioeconomic position show greater inequalities in mortality

- Health inequalities have been shown in all countries that collect the relevant data

- Social selection and measurement artefacts do not account for mortality differentials

- Social class differences exist for health during life as well as for length of life

- Trends in the distribution of income suggest that further widening of mortality differentials may be expected

infant mortality seemed to be narrowing in the late 1970s. ${ }^{4}$ Subsequent analysis, however, has suggested that this was largely due to the exclusion from the social class data of children born outside of marriage.${ }^{12}$ Births registered to both parents were included in the analyses for $1979-80$ and $1980-2,{ }^{13}$ and firm conclusions regarding more recent trends can be reached only when data for the late 1980s are analysed in this manner. Meanwhile it seems that inequalities in perinatal mortality have persisted as the overall mortality has fallen, while in the post-neonatal period differentials have narrowed as a result of mortality in babies with fathers from the non-manual classes levelling off. ${ }^{14-16}$

\section{ALTERNATIVE INDICES OF SOCIOECONOMIC POSITION}

The mortality follow up of a $1 \%$ sample from the 1971 census in the Office of Population Censuses and Surveys longitudinal study has allowed the differential mortality associated with social class to be compared with that associated with other measures of socioeconomic position. ${ }^{17}$ It has been shown that not being a home owner, not having access to a car, having a lower educational level, and being in a lower social class group are all related to higher mortality, and these effects are partially independent of each other..$^{18}$ Access to a car seems to be the single most important factor in this respect, ${ }^{18}$ and may reflect its utility in classifying groups with different income levels. Enriching the indices of socioeconomic position beyond social class has proved particularly valuable in exploring differential mortality in women, for whom both own and spouse's social class are limited measures of socioeconomic position. ${ }^{19} 20$

Excess mortality in the north of England and in Scotland is largely independent of the social class distributions of these regions. This could reflect the inadequacy of the Registrar General's Classification as an index of material wellbeing. Relative deprivation indices including car ownership, housing quality,
Correspondence to: Dr Davey Smith.

Br.Med F 1990;301:373-7 
and unemployment levels account for much of this differential in mortality..$^{21-23}$ This suggests that socioeconomic position rather than geographical location is the important factor.

Large mortality gradients have been found in occupational cohorts when the use of indices such as employment grade has produced groups that are more homogeneous with respect to material wellbeing. In male civil servants in London employment grade and car ownership contributed independently to mortality. ${ }^{24}$ Clerical staff without cars had a mortality over three times that of car owning administrators. Both administrators and clerical workers fall into the non-manual social class groups. In the general population at this time the greatest differential within middle aged men in the non-manual groups, that between class III non-manual and class I, was only $30 \%{ }^{5}$ A study of deaths from coronary heart disease in the British army produced similar results. The standardised mortality ratio from this disease was 33 in direct entry officers, 100 in officers promoted from the ranks, 123 in senior non-commissioned officers, and 205 in junior non-commissioned officers and privates. ${ }^{25}$ Around this time the standardised mortality ratios for coronary heart disease in the general population were 88 in social class I and 111 in social class V. ${ }^{5}$ Improved categorisation of socioeconomic position thus produces groups with mortality differentials considerably greater than those reported in the decennial supplements and used in the Black report.

\section{Morbidity}

Scant data on morbidity were available for use in the Black report. One source, the general household survey, has continued to appear annually, and rates of self reporting of "long standing illness" among 16-64 year old men ranged from $27 \%$ of professionals to $41 \%$ of unskilled manual men in 1987, the most recent year. ${ }^{26}$. The measures of morbidity in the general household survey are limited, however, and considerably richer data are provided by surveys that have related a wide range of measures of health state to socioeconomic position. The prevalence of angina was almost twice as high in manual compared with nonmanual middle aged men in the British regional heart study. ${ }^{27}$ Systolic blood pressure in the same study was on average more than $6 \mathrm{~mm} \mathrm{Hg}$ higher in class $\mathrm{V}$ participants than in class I participants. ${ }^{28}$ In the health and lifestyle survey a forced expiratory volume in one second more than two standard deviations below the value predicted on the basis of age and height was found in $10 \%$ of men in professional and managerial classes compared with $20 \%$ of men in semiskilled and unskilled occupations. ${ }^{29}$ Middle aged subjects in social classes IV and V reported $50 \%$ higher rates of angina in the Welsh heart health survey than did subjects from classes I and II and twice their rates of respiratory symptoms. ${ }^{30}$ Measured lung function was also worse in the manual groups, an association that was partly independent of differential prevalence of smoking. ${ }^{31}$

Surveys using self reports alone find differences in the same direction as those that include clinical measurements. Higher levels of pain, tiredness, sleep disturbance and emotional distress among the manual groups have been found in studies using the Nottingham health profile..$^{32}{ }^{33}$ Similarly, the higher reporting rates for longstanding illness in manual groups in the general household survey has received some support from a more detailed study that found a rate of reported disability in social class $\mathrm{V}$ that was more than twice that in social class $\mathrm{I} .{ }^{34}$ The extent and generality of the morbidity differences seen in these studies as a whole show that the social class differentials in mortality are preceded by inequalities in health during life.
The different implications of ill health across social groups have also been investigated. The shorter life span in less privileged groups seems to go with a longer period in poor health. Further, a given state of chronic illness is more likely to force manual than non-manual workers into economic inactivity, ${ }^{35}$ with further consequences for quality of life. Such inequalities in the consequences of disease are also seen when prognosis is examined. For most cancers, patients in non-manual groups survive longer after diagnosis than do those in poorer circumstances. ${ }^{36} 37$

\section{International comparisons of health inequalities}

Since the Black report was published there have been several studies that make possible tentative international comparisons of mortality differentials. The mortality of unskilled men in Denmark, Finland, and Norway was found to be about $50 \%$ higher than the average mortality in all occupied men, and roughly twice that in professionals and others with a university education. ${ }^{38}$ In France the mortality in unskilled workers at ages 35-44 was found to be four times that in higher managers and professionals, with this difference narrowing to just over twice at ages 55-64. ${ }^{39}$ In Denmark and Norway the excess mortality in unskilled workers was primarily due to accidents; in Finland to accidents and cardiovascular disease; in France to cancer, cirrhosis, and accidents; in England and Wales to accidents, cardiovascular disease, cancer, and respiratory disease ${ }^{40}$; and in Japan to accidents and cerebrovascular disease. ${ }^{41}$ In Australia, ${ }^{42} \mathrm{New}$ Zealand, ${ }^{43}$ and Switzerland ${ }^{45}$ analysis of mortality by occupational group showed relations similar to those in Britain, with raised mortality among manual groups being seen for most causes of death.

Educational opportunity is strongly related to the socioeconomic position of parents. Mortality differentials according to educational level have beer. compared in Hungary, Finland, England and Wales, Denmark, Sweden, and Norway. ${ }^{46}{ }^{47}$ In these countries there is a definite gradient such that more years of education are associated with lower mortality among men. A similar but less consistent relation was seen in women. For all these countries except Hungary changes in mortality differentials between the early and late 1970s could be examined. Widening of inequalities over this period were noticeable only for England and Wales.

The social class differences in mortality and morbidity that are found in Britain are thus present in many other countries with a similar social structure. There are formidable problems in producing valid comparisons of the magnitude of mortality differentials, but there have been attempts to do so. Differentials in England and Wales seem to be less than in France ${ }^{39}$ but greater than in Sweden. ${ }^{48}$ The difference between France and England and Wales was considered to reflect the different degrees of inequality in income between these countries, ${ }^{39}$ and the current ranking of mortality differentials does follow that of inequalities in income, with the bottom $40 \%$ of the populations receiving $17 \%$ of income in France, $18.5 \%$ in Britain, and $20.5 \%$ in Sweden. ${ }^{49}$

It is even more difficult to make international comparisons of morbidity differentials. ${ }^{50}$ When the Nottingham health profile was used in an Australian survey, ${ }^{\text {s1 }}$ however, the socioeconomic differentials in morbidity were similar to those in British studies. ${ }^{32} 33$ In Sweden, social class differences in the rates of limiting longstanding illness exist but are narrower than those in Britain, ${ }^{52}$ which may reflect the extent of income inequality and variations in the consistency with which welfare state policies have been pursued in the two countries. ${ }^{48}$ 


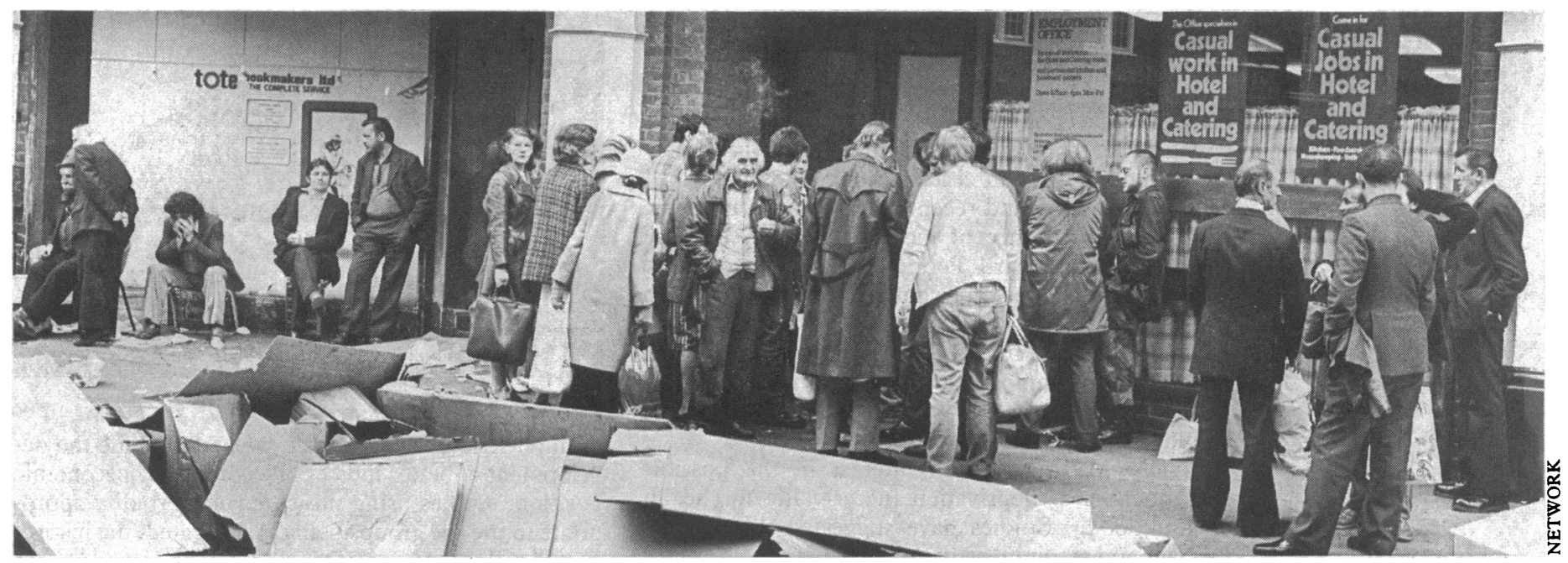

The Black report identified four types of explanations of health inequalities: artefact, selection, cultural or behavioural, and materialist. ${ }^{53}$ Since 1980 considerable advances have been made in exploring the relevance of these different types of explanation.

A simple artefact explanation holds that the mortality differentials are due to numerator-denominator bias arising because social class may be assigned differently on the death certificate (numerator) than at the census (denominator). If manual class is more likely to be recorded at death than during life the mortality differentials in the decennial supplements could be artefactual. This problem has been overcome in the Office of Population Censuses and Surveys longitudinal study by using social class as assigned at the 1971 census to categorise individuals at death. Eliminating numerator-denominator bias in this way was found to have no effect on the mortality differentials. ${ }^{17}$ Similarly, the suggestion that the reclassification of social class at the time of each census sustains gradients ${ }^{545}$ is not compatible with the findings of the longitudinal study. ${ }^{1756} \mathrm{~A}$ different type of artefact explanation is put forward to explain the widening of differentials over time. ${ }^{16}$ This suggests that as the size of the lower class groups decreases these groups will come to contain a greater proportion of people at high risk of dying. The construction of ever smaller groups containing a fixed number of subjects at high risk of dying would lead to apparently widening inequalities. Men in social class $\mathrm{V}$ could be seen as such a group: in the longitudinal study they had a standardised mortality ratio of 125 but contributed only $5 \%$ of all deaths. ${ }^{18}$ The use of alternative measures of socioeconomic position allows for the definition of larger groups that are nevertheless found to have similarly raised mortality. Men without access to a car and in rented accommodation contribute $21 \%$ of all deaths but have a standardised mortality ratio of $123-$ virtually the same as that in social class $\mathrm{V} .{ }^{18}$

Explanations in terms of selection suggest that health state in some way determines socioeconomic position. Thus the unhealthy may be downwardly socially mobile, leading to a concentration of people with a higher risk of dying among groups of low socioeconomic status. This process could also occur through selective marriage, with less healthy women marrying down the social hierarchy. Theoretical expositions ${ }^{57}$ and some data ${ }^{58}$ have been advanced to support these notions, which are sometimes advanced in a strongly eugenic form. ${ }^{59}$ The availability of social class data from the 1971 and 1981 censuses for participants in the longitudinal study has made it possible to explore the relation between social mobility and mortality. These analyses show that downward social mobility does not account for the differentials. ${ }^{560}$
There has been considerable interest in the possibility that health related behaviours-particularly cigarette smoking, diet, and lack of exercise-lead to the inequalities in health. Certainly the higher rates of cigarette smoking among the manual groups ${ }^{61}$ will contribute to poor health, although it must be remembered that earlier in this century the class gradient for cigarette smoking was reversed, ${ }^{62}$ though differentials of all cause mortality were similar to the present. ${ }^{63}$ Social class differences in consumption of fat are small ${ }^{64}$ and not necessarily in the direction that would be expected to increase the risk of coronary heart disease, though lower consumption of vitamin C, carotene, and fibre along with a higher dietary sodium to potassium ratio ${ }^{65}$ among the manual classes could be detrimental to health. The relative influence of leisure time and occupational activity on the risk of heart disease is still unresolved ${ }^{66}$ Thus the predicted effects of the finding that people in manual groups perform less exercise in leisure time but more exertion at work $^{3067}$ are not obvious.

\section{Socioeconomic gradients}

The causes of the socioeconomic gradient in the rates of coronary heart disease have been specifically investigated. Different prevalences of smoking are considered to be particularly important in this regard.$^{68}$ In the British regional heart study social class differences in smoking behaviour and blood pressure accounted for much of the gradient. ${ }^{27}$ The residual associations between social class and the incidence of coronary heart disease seen after adjustment for risk factors were suggested to be due to the inaccuracy inherent in using single measurements of risk factors as proxy measures of lifetime exposure. This is possible, but it is also the case that using social class alone leads to an underestimate of the strength of the relation between socioeconomic position and mortality, as the results of the longitudinal study make clear. In the Whitehall study the differential mortality from coronary heart disease by employment grade and car ownership could not be accounted for by differences in smoking, blood pressure, cholesterol concentration, glucose intolerance, height, or prevalent disease. ${ }^{24}{ }^{69}$ Similar results have been reported from other studies. ${ }^{7071}$ The risk of death from most causes, including those not related to "lifestyle," tends to be higher in less privileged groups, ${ }^{42} 4472$ which suggests that broader explanations should be searched for.

The Black report described as materialist those explanations emphasising hazards inherent in society, to which some people have no choice but to be exposed given the present distribution of income and opportunity. In the light of the report's stated preference for 
this type of explanation, and the strong ecological correlations between material deprivation and both mortality and morbidity ${ }^{21-23}$ it is remarkable that it has been the subject of relatively little research during the past decade. The health damaging effects of physicochemical exposures in certain occupations have long been recognised, ${ }^{73}$ and recent research has shown the additional importance of income ${ }^{74}$ and psychosocial factors ${ }^{75-77}$ in this regard. Poor quality housing or damp housing, or both, has been shown to be associated with worse health, and particularly with higher rates of respiratory disease in children. ${ }^{78-81}$ The men who were recorded as unemployed in the 1971 census and their wives - were found to have a higher mortality than employed men and their wives. ${ }^{82}$

Finally, there has been interest in the possible consequences of deprivation in early life for health in adulthood. ${ }^{83}$ Studies have suggested that cardiovascular and respiratory disease may have their origins in adverse conditions during development. ${ }^{84-86}$ Thus differential degrees of deprivation in childhood could contribute to inequalities in health in later life. As poor circumstances in early life are related to poor circumstances in adulthood, however, it is difficult to separate out the relative influence of these two factors on health. ${ }^{24} 87$

\section{Conclusions}

Since the appearance of the Black report numerous studies have contributed to a broader understanding of the extent of health inequalities. ${ }^{16}$ In particular, the importance of differentials in quality of life-in addition to length of life-has been shown. A key contribution of the Black report was the specification of different potential explanations for health inequalities. Accounts in terms of behavioural factors have been most discussed. At the same time, the economic and social constraints on lifestyles have been recognised. The effect of low income renders it meaningless to consider diet a matter solely of choice. ${ }^{88}$ Similarly, how smoking can compensate for and make bearable the consequences of material deprivation has been investigated. ${ }^{89}$

The acceptance that behaviours are not autonomous has led to the suggestion that the materialist and behavioural explanations cannot be separated. ${ }^{90}$ This is unhelpful because, although it intends to emphasise the social rootedness of lifestyles, such theorising tends to discount any influence of the social and material environment that is not mediated through behavioural patterns. Thus intervention becomes reduced to developing culturally sensitive methods for encouraging changes in lifestyle and neglects the possibility of change in the environment. The demonstration that behavioural factors have a considerably stronger influence on health in those in good material circumstances than those in poor circumstances ${ }^{9}$ emphasises the need to keep the materialist and behavioural explanations conceptually distinct.

A striking fact emerging from studies of differential mortality is the extent to which differentials continue into the privileged groups. This is clearly seen in the longitudinal study, in which the non-manual, home owning group with two cars has lower mortality than that with only one car..$^{18}$ Similarly, among top grade civil servants higher and lower mortality groups can be discerned. ${ }^{24}$ The notion of a dispossessed and feckless underclass that "imposes costs on the rest of society" and is to blame for most social ills is becoming increasingly popular. ${ }^{22}$ Such an idea has obvious consequences for social policy, yet it sits uneasily with the evidence from studies of differential mortality, which reiterate the fact that British society is stratified to a fine grain from top to bottom.

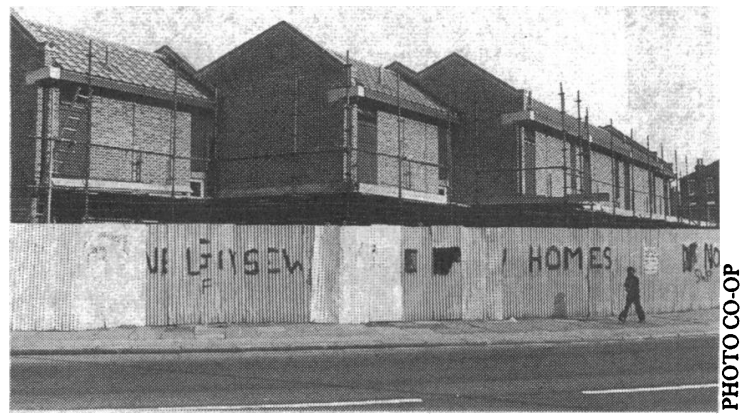

Important areas for future research include the development of better indices of women's socioeconomic position, studies using measures of morbidity appropriate to the age groups being investigated, the institution of rolling surveys of morbidity using standardised instruments that allow trends to be examined, and the establishment of data bases that allow valid international comparisons to be made. Most importantly, the neglect of the area that the Black report described as materialist should not continue. Unfortunately, the studies of the social distribution of health currently being conducted seem to be focused on the much investigated topics of lifestyles and selection.

Inequalities in mortality seem ${ }^{693}$ to have widened since the $1950 \mathrm{~s},{ }^{63}$ with this trend continuing in the early $1980 \mathrm{~s} .{ }^{56}$ What change in social class differences in mortality can then be expected between 1981 and 1991 as a result of wider social changes during this period? Government statistics show a move towards greater inequality in the distribution of income after tax between 1981 and $1985 . .^{94}$ The numbers in poverty increased from 12 million on or close to Supplementary Benefit levels in 1979 to over 15 million in $1985 .^{95}$ Although the definition of poverty has been changed, it seems that these trends have continued up to the latest available date, $1987 . .^{96}$ The fall in unemployment since 1985 would be expected to reduce the numbers in poverty, although this effect has probably been counterbalanced by a decline in the numbers of older men in work, an increase in the numbers on low earnings, a decline in the number of earners in low income families, and an increase in the number of one parent families. ${ }^{97}$ There is uncertainty about the length of the time lag between changes in material circumstances and changes in mortality. Despite this, on the basis of the general tendency towards wider material inequality, the 1991 decennial supplement may be expected to show further widening of social class differences in mortality. If so, the relevance of the Black report is increasing rather than decreasing with time.

We thank the following for their comments on an early draft: Diana Kuh, David Leon, Alison Macfarlane, Jerry Morris, and Michael Wadsworth.

1 Department of Health and Social Security. Inequalities in health: report of a research working group. London: DHSS, 1980.

2 Deitch R. Unwanted legacy from Mr. Jenkins' predecessor. Lancet 1980;ii: 545

3 Anonymous. Equalities and inequalities in health [Editorial]. $\mathrm{Br} \mathrm{Med} f$ 1980;281:762-3.

4 Townsend P, Davidson N. Inequalities in health: the Black report. Harmondsworth: Penguin, 1982.

5 Office of Population Censuses and Surveys. Occupational mortality 1970-1972. London: HMSO, 1978.

6 Office of Population Censuses and Surveys. Occupational mortality, decennial supplement 1979-1980, 1982-1983. London: HMSO, 1986.

7 Anonymous. Lies, damned lies and suppressed statistics [Editorial]. Br Med 7 1986;293:349-50.

8 Marmot MG, McDowall M. Mortality decline and widening social inequalities. Lancet 1986;ii:274-6.

9 Fox AJ, Goldblatt PO, Jones DR. Social class mortality differentials: artefact, selection or life circumstances? $\mathcal{F}$ Epidemiol Community Health 1985;39:1-8.

10 Romeder JM, McWhinnie JR. Potential years of life lost between ages 1 and 70: an indicator of premature mortality for health planning. Int $\mathcal{F}$ Epidemiol 1977;6:143-51. 
11 Blane D, Davey Smith G, Bartley M. Social class differences in years of potential life lost: size, trends, and principal causes. $\mathrm{Br} M e d \mathcal{f}$ (in press).

12 Pamuk ER. Social class inequality in infant mortality in England and Wales from 1921 to 1980. European fournal of Population 1988;4:1-21

13 Office of Population Censuses and Surveys. Occupational mortality 1979-1980, 1982-1983: childhood supplement. London: HMSO, 1988.

14 Macfarlane A, Mugford M. Birth counts: statistics of pregnancy and childhood. London: HMSO, 1984

15 Radical Statistics Health Group. Equal health for all? In: Facing the figures: what really is happening to the National Health Service. London: Radical Statistics, 1987.

16 Townsend P, Davidson N, Whitehead M. Inequalities in health: the Black report and the health divide. Harmondsworth: Penguin, 1988

17 Fox J, Goldblatt PO. Longitudinal study: socio-demographic mortality differentials. London: HMSO, 1982.

18 Goldblatt P. Mortality and alternative social classifications. In: Longitudinal study: mortality and social organisation. London: HMSO, 1990:163-92.

19 Moser K, Goldblatt P, Pugh H. Occupational mortality of women in employment. In: Goldblatt $\mathrm{P}$, ed. Longitudinal study: mortality and social organisation. London: HMSO, 1990:129-44.

20 Moser K, Pugh H, Goldblatt P. Mortality and the social classification of women. In: Goldblatt P, ed. Longitudinal study: mortality and social organisation. London: HMSO, 1990:145-62.

21 Carstairs V, Morris R. Deprivation: explaining differences in mortality between Scotland and England and Wales. Br Med f 1989;299:886-9.

22 Carstairs V, Morris $M$. Deprivation and mortality: an alternative to social class? Community Med 1989;11:210-9.

23 Townsend $\mathrm{P}, \mathrm{Phillimore} \mathrm{P}$, Beattie $\mathrm{A}$. Health and deprivation: inequality and the north. London: Croom Helm, 1988.

24 Davey Smith G, Shipley MJ, Rose G. The magnitude and causes of socioeconomic differentials in mortality: further evidence from the Whitehal study. $\mathcal{I}$ Epidemiol Community Health (in press).

25 Lynch P, Oelman BJ. Mortality from coronary heart disease in the British army compared with the civil population. Br Med f 1981;283:405-7.

26 Office of Population Censuses and Surveys. General household survey 1987. London: HMSO, 1989

27 Pocock SJ, Shaper AG, Cook DG, Phillips AN, Walker M. Social class differences in ischaemic heart disease in British men. Lancet 1987;ii 197-201.

28 Shaper AG, Ashby D, Pocock S. Blood pressure and hypertension in middleaged British men. I Hypertension 1988;6:367-74.

29 Cox BD, Blaxter M, Buckle ALJ, et al. The health and lifestyle survey: preliminary report. London: Health Promotion Research Trust, 1987.

30 Nutbeam D, Catford J. Pulse of Wales: social survey supplement. Cardiff: Heartbeat Wales, 1987

31 Nutbeam D, Catford J, Davey Smith G. Hearl of Wales: clinical results of the Welsh heart health survey 1985. Cardiff: Heartbeat Wales, 1988.

32 Hunt S, McEwen J, McKenna SP. Social inequalities in perceived health. Effective Health Care 1985;2:151-60.

33 Bucquet $D$, Curtis $S$. Socio-demographic variation in perceived illness and the use of primary care. Soc Sci Med 1986;23:737-44.

34 Patrick D, Charlton J, Locker D, et al. Health and care of the physically handicapped in Lambeth. London: St Thomas's Hospital and Medical School, 1980

35 Bartley MJ. Health and labour force participation. Fournal of Social Policy (in

press).
36 Kogevinas E. Longitudinal study: socio-demographic differences in cancer survival. London: HMSO, 1990

37 Leon D, Wilkinson RG. Inequalities in prognosis: socio-economic differences in cancer and heart disease survival. In: Fox J, ed. Health inequalities in European countries. Aldershot: Gower, 1989:280-300.

38 Lynge E. Occupational mortality in Norway, Denmark and Finland 1971-1975. In: Committee for International Cooperation of National Research in Demography, ed. Socio-economic differential mortality in industrialised societies. Paris: World Health Organisation, 1981.

39 Leclerc A, Lert F, Goldberg $M$. Les inégalites sociales devant la mort en Grande-Bretagne et en France. Soc SciMed 1984:19:479-87.

40 Leclerc A. Differential mortality by cause of death: comparisons between selected European countries. In: Fox J, ed. Health inequalities in European countries. Aldershot: Gower, 1989:92-108.

41 Kagamimori S, Libuchi Y, Fox J. A comparison of socioeconomic differences in mortality between Japan and England and Wales. World Health Stat $Q$ 1983;36:119-28.

42 Najman JM, Congalton AA. Australian occupational mortality, 1965-1967: cause specific or general susceptibility? Sociology of Health and Illness 1979;1:158-76.

43 Pearce NE, Davis PB, Smith AH, Foster FH. Mortality and social class in New Zealand. I: Overall male mortality. $N Z$ Med f 1983;96:281-5.

44 Pearce NE, Davis PB, Smith AH, Foster FH. Mortality and social class in New Zealand. II. Male mortality by major disease groupings. $N \mathrm{Z} \mathrm{Med} \mathcal{f}$ 1983;96:711-6.

45 Lehmann P, Mamboury C, Minder CE. Health and social inequities in Switzerland. Soc Sci Med 1990;31:369-86.

46 Lahelma E, Valkonen T. Health and social inequities in Finland and elsewhere Soc Sci Med 1990:31:257-65.

47 Valkonen T. Adult mortality and level of education: a comparison of six countries. In: Fox J, ed. Health inequalities in European Countries. Aldershot: Gower, 1989:142-62.

48 Vagero $\mathrm{D}$, Lundberg $\mathrm{O}$. Health inequalities in Britain and Sweden. Lancel 1989;ii:35-6.

49 World Bank. World development report 1989. New York: Oxford University Press, 1989.

50 Aiach $\mathrm{P}, \mathrm{Curtis} \mathrm{S}$. Social inequalities in self-reported morbidity: interpretation and comparison of data from Britain and France. Soc Sci Med 1990;31 $267-74$

51 Baum. FE, Cooke RD. Community-health needs assessment: use of the Nottingham health profile in an Australian study. Med f Aust 1989;150

52 Lunberg O. Class and health: comparing Britain and Sweden. Soc Sci Med 1986;23:511-7.
53 Blane D. An assessment of the Black report's "explanations of health inequalities." Sociology of Health and Illness 1985; 7:423-45.

54 Jones IG, Cameron D. Social class: an embarrassment to epidemiology? Community Med 1984;6:37-46.

55 Bloor M, Samphier M, Prior L. Artefact explanations of inequalities in health: an assessment of the evidence. Sociology of Health and Illness 1987;9:231-64. 6 Goldblatt P. Mortality by social class, 1971-85. Population Trends 1989;56: 6-15

57 Stern J. Social mobility and the interpretation of social class mortality differentials. Joumal of Social Policy 1983;12:27-49.

58 Illsley R. Occupational class, selection and the production of inequalities in health. Quarterly fournal of Social Affairs 1986;2:151-65.

59 Himsworth H. Epidemiology, genetics and sociology. J Biosoc Sci 1984;16: $159-76$

60 Goldblatt $O$. Changes in social class between 1971 and 1981: could these affect mortality differentials among men of working age? Population Trends 1988;51:9-17.

61 Office of Population Censuses and Surveys. General household survey 1988. London: HMSO, 1990

62 Simpson $\mathrm{O}$. Trends in major risk factors: cigarette smoking. Postgrad Med $\mathcal{J}$ 1984;60:20-5.

63 Pamuk ER. Social class inequality in mortality from 1921 to 1972 in England and Wales. Population studies 1985;39:17-31.

64 Gregory J, Foster K, Tyler H, Wiseman M. Dietary and nutrition survey of British adults. London: HMSO, 1990.

65 Williams DDR, Bingham SA. Sodium and potassium intakes in a representative population sample: estimation from 24 hour urine collections known to be complete in a Cambridgeshire village. Br $\mathcal{F}$ Nutr 1986;55:13-22.

66 Powell KE, Thompson PD, Caspersen CJ, Kendrick JK. Physical activity and the incidence of coronary heart disease. Ann Rev Public Health 1987;8: 253-87.

67 Office of Population Censuses and Surveys. General household survey for 1983. London: HMSO, 1985.

68 Baker IA, Sweetnam PM, Yarnell JWG, Bainton D, Elwood PC. Haemostatic and other risk factors for ischaemic heart disease and social class: evidence from the Caerphilly and Speedwell studies. Int $\mathcal{X}$ Epidemiol 1988;17:759-65.

69 Marmot MG, Rose G, Shipley M, Hamilton PJS. Employment grade and coronary heart disease in British civil servants. $\mathcal{f}$ Epidemiol Community Health 1978;32:244-9.

70 Salonen J. Socioeconomic status and risk of cancer, cerebral stroke, and death due to coronary heart disease and any disease: a longitudinal study in eastern Finland. I Epidemiol Community Health 1982;36:294-7.

71 Haan M, Kaplan GA, Camacho T. Poverty and health: prospective evidence from the Alamada county study. Am $\mathcal{F}$ Epidemiol 1987;125:989-98.

72 Marmot MG, Shipley MJ, Rose G. Inequalities in death-specific explanations of a general pattern? Lancet 1984;i:1003-6.

73 Hunter D. The diseases of occupations. London: Hodder and Stoughton, 1955.

74 Wilkinson RG. Class mortality differentials, income distribution and trends in poverty 1921-1981. Fournal of Social Policy 1989;18:307-35.

75 Karasek R, Baker D, Marxer F, Ahlbom A, Theorell T. Job decision latitude, job demands and cardiovascular disease: a prospective study of Swedish men. Am f Public Health 1981;71:694-705.

76 Alfredsson L, Spetz CL, Theorell T. Type of occupation and near-future hospitalization for myocardial infarction and some other diagnoses. Int $\mathcal{J}$ Epidemiol 1985;14:378-88.

77 Marmot MG, Theorell T. Social class and cardiovascular disease: the contribution of work. Int $\mathcal{F}$ Health Serv 1989;18:659-74.

78 McCarthy P, Byrne D, Harrison S, Keithley J. Respiratory conditions: effec of housing and other factors. I Epidemiol Community Health 1985;39:15-9.

79 Martin CJ, Platt SD, Hunt S. Housing conditions and health. Br Med $\mathcal{J}$ 1987;294:1125-7.

80 Platt SD, Martin CJ, Hunt S, Lewis CW. Damp housing, mould growth and symptomatic health state. $\mathrm{Br}$ Med $\mathcal{F}$ 1989;298:1673-8.

81 Lowry S. Housing and health: temperature and humidity. Br Med 1989;299:1326-8

82 Moser K, Goldblatt P, Fox J, Jones D. Unemployment and mortality. In Goldblatt $\mathrm{P}$, ed. Longitudinal study: mortality and social organisation. London: HMSO, 1990:81-97.

83 Forsdahl A. Are poor living conditions in childhood and adolescence an important risk factor for arteriosclerotic heart disease? $\mathrm{Br} \mathcal{F}$ Prev Soc Med 1977;31:91-5.

84 Forsdahl A. Living conditions in childhood and subsequent development of risk factors for arteriosclerotic heart disease. The cardiovascular survey in Finnmark 1974-75. J Epidemiol Community Health 1978;32:34-7.

85 Barker DJP, Winter PD, Osmond C, Margetts B, Simmonds SJ. Weight in infancy and death from ischaemic heart disease. Lancet 1989;ii:577-80.

86 Barker DJP, Osmond C. Childhood respiratory infection and adult chronic bronchitis in England and Wales. Br Med f 1986;293:1271-5.

87 Williams DRR, Roberts SJ, Davies TW. Deaths from ischaemic heart disease and infant mortality in England and Wales. $\mathcal{F}$ Epidemiol Community Health 1979;33:199-202.

88 Cole-Hamilton I Lang $T$. Tightening belts: a report on the impact of poverty on food. London: London Food Commission, 1986

89 Graham H. Women's smoking and family health. Soc SciMed 1987:25:47-56.

90 MacIntyre S, Annandale E, Ecob R, et al. The West of Scotland Twenty-07 Study: health in the community. In: Martin CJ, McQueen DV, eds. Readings for a new public health. Edinburgh: Edinburgh University Press, 1989:56-74

91 Blaxter M. Health and lifestyle. London: Tavistock/Routledge, 1990.

92 Anonymous. The underclass [Editorial]. Lancet 1990;335:1312-3.

93 Hansluwka H. Reflections on the measurement of social inequality of death. In: New developments in the analysis of mortality and causes of death. Geneva: World Health Organisation, 1986:121-52.

94 Central Statistical Office. Social trends 1988. London: HMSO, 1989

95 Department of Health and Social Security. Low income families. London: DHSS, 1988

96 Government Statistical Service. Households below average income--a statistical analysis 1981-1987. London: HMSO, 1990.

97 Piachaud D. Poverty and social security. Inaugural lecture. London: London School of Economics, 1990 